\title{
MAIS RÁPIDAS QUE A ESCOLA: CRIANÇAS REFERIDAS COMO HIPERATIVAS NO CONTEXTO ESCOLAR
}

\author{
MÁS RÁPIDAS QUE LA ESCUELA: NIÑOS REFERIDOS COMO \\ HIPERACTIVOS EN EL CONTEXTO ESCOLAR
}

\author{
FASTER THAN A SCHOOL: CHILDREN REFERRED TO AS HYPERACTIVE \\ IN SCHOOL CONTEXT
}

\author{
Cláudia Rodrigues de FREITAS ${ }^{1}$ \\ Claudio Roberto BAPTISTA ${ }^{2}$
}

RESUMO: Este trabalho analisa os discursos que identificam um número expressivo de crianças como hiperativas na Educação Infantil da Rede Municipal de Ensino de Porto Alegre. O conceito de normalidade teve como base o pensamento de Canguilhem e Foucault em sintonia com as proposições de Gregory Bateson. Considerando a contínua articulação entre normal e anormal busca-se a construção do conceito de Transtorno de Déficit de Atenção com Hiperatividade - TDAH. Uma análise cartográfica da atenção evidencia esta, em seu movimento circular de invenção, como efeito da/na aprendizagem. Dentre as evidências, uma das mais importantes é: a responsável por associar hiperatividade a uma dimensão de desamparo, dirigida não só ao sujeito criança, mas a todos os implicados nessa rede.

PALAVRAS-CHAVE: TDAH. Hiperatividade. Atenção. Inclusão Escolar. Educação Infantil.

RESUMEN: Este trabajo analiza los discursos que identifican un número expresivo de niños como hiperactivos en la Educación Infantil de la Red Municipal de Enseñanza de Porto Alegre. El concepto de normalidad tuvo como base el pensamiento de Canguilhem y Foucault asociado al de Bateson. Considerando la continua articulación entre normal y anormal se busca la construcción del concepto de Trastorno de Déficit de Atención con Hiperactividad TDAH. Un análisis cartográfico de la atención evidencia esta idea no como condición previa, sino como movimiento circular de la invención, como efecto del/en el aprendizaje. Entre las evidencias, una de las más importantes es: la responsabilidad por asociar hiperactividad a una dimensión de desamparo, dirigida no solamente al niño, sino a todos los implicados en esta red.

PALABRAS CLAVE: TDAH. Hiperactividad. Atención. Inclusión Escolar. Educación Infantil.

\footnotetext{
${ }^{1}$ Universidade Federal do Rio Grande do Sul (UFRGS), Porto Alegre - RS - Brasil. Programa de Pós-Graduação em Educação. Doutora em Educação. ORCID: <https://orcid.org/0000-0002-7105-8539>. E-mail: freitascrd@gmail.com

${ }^{2}$ Universidade Federal do Rio Grande do Sul (UFRGS), Porto Alegre - RS - Brasil. Programa de Pós-Graduação em Educação. Doutor em Educação. ORCID: 〈https://orcid.org/0000-0001-6673-4574>. E-mail: baptistacaronti@yahoo.com.br
} 
ABSTRACT: This work analyzes the several discourses that identify a significant number of children as hyperactive in Child Education in the Schools of the City of Porto Alegre. In order to substantiate the searches, some essential concepts were developed. The concept of normalcy, based on the thinking of Canguilhem and Foucault, is associated to the systemic thinking of Gregory Bateson. Considering the continuous articulation between normal and abnormal, the construction of the concept of Attention Deficit Hyperactivity Disorder ADHD A cartographic analysis of attention, evidences understood Attention not as a condition precedent, but within its circular invention movement, as an effect of and in learning. Among the evidences, one of the most important is the one that identifies hyperactivity associated to a dimension of abandonment, focused not only on the subject child but also on all of those affected in this network.

KEYWORDS: ADHD. Hyperactivity. Attention. Child Education. School Inclusion.

\section{Introdução}

Hiperatividade. Uma palavra. Um diagnóstico. Nas últimas duas décadas, um número expressivo de crianças tem sido assim identificado pelos discursos produzidos na escola. Em forma de epidemia o discurso escolar encaminha crianças aos consultórios médicos. Qual seria a intenção subjacente? Há mudanças na organização pedagógica a partir do diagnóstico ou do laudo médico? O que denuncia ou anuncia o corpo? O que é do singular e o que é construído na cultura? Como se engendram as relações que se manifestam nesse corpo?

O presente trabalho analisa os discursos e os processos pedagógicos associados à Educação Infantil e às crianças identificadas como hiperativas. Interessa-nos conhecer como a ação organizada no âmbito dos apoios educacionais integra um processo complexo que identifica e, contemporaneamente, produz as crianças com diagnóstico de TDAH Transtorno de Déficit de Atenção com Hiperatividade - na escola. Nesse sentido, a questão central da pesquisa pode ser assim anunciada: O que acontece com o saber e o não saber da educação face às “crianças que não param”?

Buscamos entender como a educação trabalha com aqueles denominados "hiperativos". De quais recursos lança mão para tratar essa questão? A educação cria um corpus de conhecimento ou apenas convoca o saber médico?

Partíamos da compreensão de que, apesar da evidência de que há um destaque conferido à medicina e demais áreas da saúde, a produção do sujeito com características de hiperativo está implicada em uma complexa rede de diferentes olhares e muitos atores, dentre os quais a escola ocupa uma posição fundamental, tanto na sinalização daquilo que emerge, o 
primeiro olhar identificador, quanto na potencial oferta de acolhimento para o sofrimento desencadeado.

Consideramos alguns conceitos fundamentais para a sustentação de nosso olhar na pesquisa. O de normalidade, tendo como base o pensamento de Canguilhem (2000) e Foucault (2002), associa-se ao pensamento sistêmico de Gregory Bateson (1993). Parte-se da contínua articulação entre normal e anormal na busca da construção do conceito de Transtorno de Déficit de Atenção com Hiperatividade - TDAH, tomando as referências históricas e as evidências de que o diagnóstico referente a tais sujeitos se apresenta na forma de "epidemia"3 no contexto investigado.

Durante o processo de investigação, foram entrevistadas professoras implicadas na escolarização de crianças de zero a seis anos que frequentam as escolas municipais de Porto Alegre. São educadoras especiais responsáveis pelo serviço de atendimento precoce às crianças matriculadas na Educação Infantil, oferecendo acompanhamento às famílias e prestando assessoria às escolas. Trata-se de um serviço existente há 25 anos nesta cidade e envolve 14 profissionais que prestam atendimento a aproximadamente 300 crianças. $\mathrm{O}$ contato com as educadoras especiais permitiu o acesso a informações sobre um campo com 43 Escolas Municipais de Educação Infantil (EMEIs) e 264 Creches Conveniadas.

Ao longo deste trabalho, a análise teórica possibilitou o emergir de conceitos fundamentais para refletir sobre esses processos. E o fizemos por meio dos saberes atualizados em diferentes campos do conhecimento acerca das relações entre as pessoas e instituições, da atenção ao corpo e da produção de um sujeito identificado como hiperativo. Organizamos assim alguns eixos de entendimento como uma estratégia analítica que evidenciasse o cuidado e o detalhamento da pesquisa. Apresentamos a seguir os aspectos emergentes do universo teórico, para, em momento posterior, expormos os efeitos da conexão com o trabalho de campo.

Identifica-se uma fundamentação pautada no reconhecimento da historicidade do sujeito e de suas marcas. A busca dessa compreensão encontra alguém em construção durante o processo e, a partir dos elos interativos, une pessoas e contexto (BATESON, 1993). Tratase, portanto, de entender como se estabelecem possíveis fronteiras delimitadoras de algo identificável como sendo do campo da normalidade.

\footnotetext{
${ }^{3}$ Embora haja discordância na literatura especializada acerca do uso de epidemia para os fenômenos analisados, estamos nos apoiando nas reflexões de Frances (2013), conhecido psiquiatra norte-americano e coordenador do grupo de trabalho que escreveu o DSM-IV.
} 


\section{A Cartografia da Normalidade}

O conceito de norma, como nos refere Canguilhem (2000), é polêmico e deve ser procurado no tensionamento da "[...] relação normal e anormal. Não se trata de uma relação de contradição e de exterioridade, mas de uma relação de inversão e de polaridade" (CANGUILHEM, 2000, p. 212).

Na perspectiva de Foucault (2002), a norma é entendida como o elemento que circula entre o disciplinar e o regulamentador, tendo como função a capacidade de controlar e disciplinar o corpo e os acontecimentos de uma sociedade. Surge então, no século XVIII, um novo poder exercido continuamente por vigilância. Esse é o poder disciplinar, necessário para a garantia da normalidade. A disciplina traz em seu bojo o discurso da regra, o discurso da norma, e definirá o código que será o da normalização.

A normalidade vai sendo agenciada em espaços e épocas específicos a partir dos regimes de verdade enunciados. Há regimes e técnicas governando, gerenciando modos de se posicionar em diferentes épocas, locais e situações. Uma sociedade é, ao mesmo tempo, máquina e organismo (CANGUILHEM, 2000). Isso garante a dinâmica dos lugares, onde as normas imprimem o modo de se comportar e viver, mas ao mesmo tempo sempre existe a possibilidade de uma interrupção, uma nova direção.

\section{TDAH e a construção de um perfil de infância}

A cultura da medicalização ${ }^{4}$ reconhece sinais e sintomas, esquecendo o sujeito, em um movimento que se configura em um "biologismo extremo". Ao olhar para a vida infantil, reconhecemos os nomes que estão a essa vida associados como construções identitárias, com caráter homogeneizante. O conceito de Transtorno de Déficit de Atenção com Hiperatividade (TDAH) é considerado, em segmentos do meio acadêmico, como a forma de transtorno psiquiátrico mais comum na infância (ITABORAHY, 2009; CALIMAN, 2010). A perspectiva que o abriga identifica elementos como desatenção, impulsividade e hiperatividade. Frances (2013), ao discutir a publicação do DMS5 e seus efeitos, reafirma a compreensão de que esse transtorno se constitui como um dos três quadros diagnósticos em contínuo aumento, juntamente com aquele de Transtorno do Espetro do Autismo e de Transtorno Bipolar Infantil. O autor analisa as possíveis justificativas para esses aumentos e

${ }^{4}$ Medicalização, de acordo com o presente trabalho, deve ser associada a uma dinâmica que transforma a vida em objeto supostamente biológico. É “o processo de conferir uma aparência de problema de Saúde a questões de outra natureza, geralmente de natureza social” (ANGELUCCI; SOUZA, 2010, p. 9). 
para a tendência geral de patologização do cotidiano presente nos mais recentes manuais diagnósticos, destacando uma pluralidade de interesses corporativos e econômicos associados ao avanço de uma mentalidade que reduz à dimensão físico-química aquilo que deveriam ser alternativas sociais no trato com o sofrimento psíquico.

Os vários discursos sobre o TDAH funcionam como promessas. A medicina promete a cada tempo a "descoberta última" sobre sujeitos identificados como hiperativos, em uma aparente renovação que reafirma sempre o mesmo: os fundamentos biológicos ou as características intrínsecas ao sujeito.

O discurso médico parece exercer cada vez mais impacto por meio de um elenco de estratégias capazes de mantê-lo vivo e forte. Os discursos sobre TDAH vêm se acoplando a outro, mais amplo, associado à biologização e à invenção do "homem cerebral" e da ênfase nos corpos que precisariam de "otimização" (ROSE, 2008). As questões emergentes, quando observamos os efeitos desse modo de olhar e tratar a infância, têm o poder de nos propiciar outra escuta, uma maneira de agir que possibilita ressignificar diagnósticos elaborados de forma apressada. Distanciar nosso olhar do "transtorno" vai nos permitir olhar para o sujeito encarnado, datado, se construindo em relação.

Nossa reflexão não nega a importância do diagnóstico, tanto para o tratamento como para a prevenção de distúrbios. No entanto, pontuamos o excesso e as decorrências que o acompanham, em termos de rotulação e de potencial exclusão. Entendemos o diagnóstico como processo que põe em destaque a pessoa singular, com sua história e sua trajetória necessariamente vinculada a redes de pertencimento.

O poder médico ou o das instituições médicas se constrói por meio de alguns procedimentos, pelo acionamento de dispositivos que os definem como algo da ciência na modernidade. Existe um "espírito" sendo engendrado, um espírito disseminado que produz modos de pensar, como ocorre com o conceito de "mente" no pensamento de Bateson (1993).

[...] "espírito" como superfície de inscrição para o poder, com a semiologia por instrumento; a submissão dos corpos pelo controle das ideias; a análise das representações como princípio, numa política dos corpos bem mais eficaz que a anatomia ritual dos suplícios. O pensamento dos ideólogos não foi apenas uma teoria do indivíduo e da sociedade; desenvolveu-se como uma tecnologia dos poderes sutis, eficazes e econômicos, em oposição aos gastos suntuosos do poder dos soberanos (FOUCAULT, 1992, p. 93).

Poder, para Foucault (2002), possui alguns pressupostos que não são monolíticos nem estão dados a priori, mas são construídos, forjados na relação. O essencial do seu papel é 
legitimar, na forma do conhecimento científico, a extensão do poder de punir, permitindo situar a ação punitiva do poder judiciário num corpus geral de técnicas bem pensadas de transformação dos indivíduos.

Foucault (2002) analisa os discursos reconhecendo como funcionam algumas funções estabelecidas quando acontece o exame psiquiátrico. $\mathrm{O}$ autor propõe, para uma análise vertical, a construção do que ele chama de "duplo" como possibilidade de estabelecer um dobramento ao modelo. Trata-se de desdobrar os elementos na mesma cena. Vemos aqui uma aproximação entre o exame médico-legal e o exame clínico, ao qual, muitas vezes, são submetidos os sujeitos que recebem como duplo o diagnóstico de TDAH. Não são mais sujeitos, mas "TDAHs". "Se alguém introduz o diagnóstico precocemente, e trata-a como se fosse 'um TDAH', no final pode ter razão" (UNTOIGLICH, 2006, p. 16). Estabelece-se, assim, a circularidade produtiva de um fenômeno, pois a insistência presente na detecção que estaria associada ao suposto cuidado precoce acaba por ser o traço distintivo das relações que "alimentam" o fenômeno em questão.

A escola, diante da criança que não para, com muita frequência abdica de seu saber ou de sua possibilidade de investigar e ensinar, encaminhando o aluno para uma avaliação médica. Essas crianças inquietam seus professores por ocuparem o olhar desses adultos a partir do movimento de seus corpos. Quando isso acontece, e o diagnóstico frequentemente nomeia esse aluno como hiperativo, o sujeito deixa de ser "o sapeca", "o que não para", "o que aprende tudo ao mesmo tempo". Esta sigla - TDAH - funciona, como diria Foucault, como um dobramento do sujeito. Os dobramentos são duplos sucessivos que, dobrando o discurso sobre a criança, transformam-na em um diagnóstico. O nome do sujeito passa a ser o diagnóstico.

\section{O discurso da "Atenção" e o trabalho cartográfico}

Para além de um ato de investigar as supostas faltas, passamos a explorar suas relações com aquilo que o discurso pedagógico pode negar em termos de uma potência não reconhecida como intrínseca ao processo. O conceito de atenção permite discutir, como contraponto, o conceito de desatenção ou déficit de atenção. Buscamos reconhecer as mutações, os deslocamentos, as transformações e usos do conceito de atenção.

Uma análise cartográfica da atenção permite reconhecer esta não como condição prévia, mas em seu movimento circular de invenção, como efeito da/na aprendizagem. 
A partir dessa análise, encontramos em Foucault a direção que leva à possibilidade de considerar atenção como invenção. Com as argumentações de Fernández (2001), Caliman (2006) e Kastrup (2009) acerca da atenção, passamos a entender esta não apenas como concentração, mas como descentração, dispersão criativa. A atenção não é algo dado a priori, mas se produz. "Atenção como um processo múltiplo, instável, e não como um estado a ser atingido de maneira imune às perturbações internas e externas" (FREITAS; BAPTISTA, 2017, p. 6).

A atenção é um "trabalho", uma capacidade inerente ao pensar e aprender, mas precisa de regência. Não se ensina, mas se aprende. Não é prévia à aprendizagem, mas se constrói no processo de constituição da aprendizagem. Esta perspectiva nos (re)coloca como professoresprotagonistas na cena escolar. Sendo a atenção construída e inventada no processo, ela permite ao professor ocupar um lugar de ensinante e ao aluno um espaço de aprendente (FERNÁNDEZ, 2001).

Quando identificamos uma perspectiva de investigação que se mostra em sintonia com nossas lentes, destacamos procedimentos que se associam à invenção e à cartografia. Trata-se de sacudir as evidências, num processo de estranhamento que reconhece a complexidade das racionalidades enraizadas em nosso tempo, problematizando nossas formas de pensar o espaço de verdade no qual essas racionalidades foram historicamente produzidas.

Apostamos em uma metodologia capaz de valorizar a cartografia, como exercício cognitivo peculiar que "requer uma cognição muito mais capaz de inventar o mundo do que reconhecê-lo" (AMADOR; FONSECA, 2009, p. 30). Com base nessa forma de pensar, nosso exercício de pesquisar foi aquele de coletar evidências e dar algum sentido a elas.

Há uma dimensão cartográfica, na qual nos apoiamos, associada à busca de indícios, mas há também uma outra que é associada à contínua produção de intensidades de fluxos. A produção de dados, segundo Kastrup (2009), ocorre desde o início da pesquisa e segue na escrita do texto, continuando ainda na publicação dos dados. "O cartógrafo deve pautar-se, sobretudo, numa atenção sensível, para que possa, enfim, encontrar o que não conhecia, embora já estivesse ali, como virtualidade" (KASTRUP, 2009, p. 48-49).

Nossa dedicação ao processo de "produção dos dados" nos fez procurar dimensões nas quais pudéssemos pousar a nossa atenção. Como afirma Kastrup (2009), "tudo caminha até que a atenção, numa atitude de ativa receptividade, é tocada por algo" (p. 42).

A partir de nossas questões norteadoras, valorizamos o diálogo com interlocutoras imersas no trabalho pedagógico: educadoras especiais que trabalham nos serviços de 
Educação Precoce (EP) e Psicopedagogia Inicial (PI) em quatro escolas especiais existentes na Rede Municipal de Ensino de Porto Alegre (BENINCASA, 2011).

Os serviços de EP e PI são modalidades de atendimento aos bebês e crianças pequenas funcionando em escolas especiais dessa rede municipal, para as quais são encaminhadas as crianças que recebem a identificação de necessidade de apoio complementar. Todas as educadoras, além do trabalho com as crianças e com suas famílias, devem prestar assessoria às EMEIs e Creches Conveniadas, buscando a sustentação do trabalho de inclusão escolar na Educação Infantil.

Os encontros com nossas interlocutoras ocorreram inicialmente em espaço coletivo de diálogo, em uma reunião com característica de fórum de discussões da rede.

Nossas entrevistadas eram educadoras especiais com larga experiência na rede, envolvidas com o apoio especializado em educação especial destinado aos bebês e às crianças pequenas. Demos nomes fictícios a essas Educadoras Especiais: Laura, Bárbara, Regina, Lúcia e Valéria.

As entrevistas deram existência a um amplo conjunto de evidências. Fomos reunindo os indícios que se mostravam em modo insistente. Na medida em que líamos uma entrevista voltávamos às anteriores. Fomos produzindo, desde o que nós escutávamos e "traçávamos", a cartografia da pesquisa.

Colocávamos em ação uma vontade de encontrar sentidos nas práticas discursivas. A surpresa diante do campo, das evidências, permitiu ir construindo uma cartografia à medida que os enunciados desenhavam os discursos. As trilhas dessa cartografia passam a ficar mais visíveis. A seguir, em forma de análise, apresentamos os efeitos de nossa leitura e o destaque desses discursos, das possíveis sintonias com as questões discutidas com base na teoria apresentada em precedência. Trata-se de um processo de investigação que busca fazer dialogar resultados de investigações anteriores e indícios que marcam o cotidiano pesquisado.

\section{Análise}

A partir das entrevistas, houve a composição de grupos de argumentação. Estes, em forma de pequenos títulos, são chamados de Nomes-Perguntas: Quando as crianças param? Como essas crianças são referidas? Que palavras ou grupos de argumentação são usados? Dentre as evidências, uma das mais importantes é a que identifica hiperatividade associada a uma dimensão de desamparo, dirigida não só ao sujeito criança, mas a todos os implicados 
nessa rede. O desamparo é entendido como uma forma aguda de sofrimento de diversas ordens. No entanto, a partir do olhar dirigido ao contexto, foi observado que crianças neste estado, quando encontraram o cuidado e a atenção personalizada, apresentaram uma mudança traduzida em possibilidade de convivência e de aprendizagem na escola.

Buscando respostas para essas questões, passamos a considerar as muitas histórias infantis que permeiam serviços especializados de apoio pedagógico e se mostraram por meio das entrevistas. Tais entrevistas eram compostas por um roteiro aberto congregando questões que, em modo amplo, envolviam a identificação da hiperatividade e o trabalho pedagógico, mas o processo de perguntar, como previsto em uma investigação qualitativa e aberta, gerava novas interrogações.

Uma das características emergentes identifica algo compartilhado entre os diferentes atores implicados e pode ser reconhecido no desamparo como falta de sustentação, gerando e mostrando sofrimento. Desamparo compartilhado e difuso. Como esta condição se mostra nas crianças, famílias e professoras?

Possivelmente, a expressão do desamparo compartilhado seja visível na ocorrência de ações que colocam em evidência um adulto incapaz de exercer sua função na relação com a criança e vive, com sofrimento, os efeitos de uma ausência de limite. Em um relato de professora entrevistada:

A semana passada uma escola contou: mas machucou a mão da professora. Mas, então, tu lês o relato e depois vai olhar a idade da criança... Nossa, uma criança de três anos não é capaz de machucar a mão da professora. Então por isso é que eu digo, são vítimas dos alunos, são professoras frágeis. Que não toleram a criança. Então a ideia é que essas crianças fiquem fora. (Laura)

Em alguns momentos os relatos indicam possibilidades de compreensão para um movimento de produção desses sujeitos em relações que nem sempre constituem uma 'borda' delimitadora, ou se anunciam como um olhar diferente daquele esperado pela emergência do ato. Como sustentar o papel adulto necessário a um educador ou familiar?

Eu acho que a coisa do olhar... Só olha pra ele quando ele está aprontando. É preciso poder olhar em outros momentos. Então eles ficam chamando a atenção o tempo inteiro. Se tu não olhas, eles ficam te chamando a atenção. (Regina) 
As professoras constroem sua argumentação a partir da lógica que define o diagnóstico pelo comportamento da criança. Essa também é a forma como, a despeito de todo o investimento em "análises científicas" e os ditos referentes aos aspectos biológicos e cerebrais, as avaliações médicas sustentam seu diagnóstico em uma análise clínica: uma análise de comportamentos e condutas expressos nos manuais internacionais de classificação.

O diagnóstico pode ser referido por vários 'núcleos produtores', como família, escola, serviço médico. No entanto, reconhecemos que no universo de referência para esta pesquisa, o predomínio é um diagnóstico, em sua formação inicial, de responsabilidade da escola. Os indícios colhidos permitem dizer que esse primeiro diagnóstico conta com a aprovação e o incentivo médico. Sendo a professora a pessoa que está em contato cotidiano com a criança, esta é a primeira a avaliá-la. A preocupação que se desdobra é aquela de entender o quê, a partir do diagnóstico, a escola produz na organização pedagógica.

Atualmente os professores não fazem mais parecer sobre as crianças, nem relatórios. Eles dão laudos. Não sei se tu já tinha visto. Então eu recebo por e-mail laudos sobre uma criança muito pequena, bebês, um ano, dois anos. A escola infantil oferece laudos das crianças na escola. Isso tem vindo, e são umas coisas bem complicadas. Também crianças muito pequenas... Todas levam pra essa linha de transtorno. (Lúcia)

Porque se a gente for acolher e trouxer todas as crianças que dizem ser hiperativas, a escola teria que se multiplicar. Ia fazer outra escola. (Lúcia)

O impacto do diagnóstico é impregnante e tem efeitos múltiplos com potencial para produzir o sofrimento do sujeito. Sofrer no sentido de sentir-se culpado em função do "distúrbio", ou de passar a se confundir com o próprio distúrbio.

Ele não para. Ninguém... Como é? "Ninguém dá mais conta dele". É hiperativo, é agitado. Que bate! Que espanca! Que quebra. Que já botou todos os professores pra rua. Que já destruiu uma sala. Que não para. Que ninguém consegue... Que está sempre no pátio, que ninguém fica com ele dentro da sala, ninguém sabe lidar. (Lúcia)

A maior queixa é agressividade. Não aceitam não. Agressividade. Sem limites. Depois tem essa instabilidade, essa agitação. Essa falta de concentração. Parece que assim são características que se sobrepõem. Mas sempre vem a expressão: É hiperativo! (Bárbara)

A escola traz que eles não param... Que são agitados, que são desatentos, que têm dificuldade de atenção, de concentração, que ficam trocando de brinquedo o tempo todo. Hiperativos! (Regina) 
Hiperatividade, direto... Era a palavra que as pessoas mais usavam para se referir a qualquer conduta mais de agitação, fosse motora, fosse mais algo em termos de comportamento. Que é hiperativa, a gente escuta. De bebê... eu penso que as pessoas se referem muitas vezes ao comportamento agitado e já associam isso ao diagnóstico de hiperatividade. De um transtorno. Essa demanda chega muito. Hiperativos são o que elas mais usam... Criança muito inquieta. "Ele corre!" Muito indisciplinada. Bagunceira. Agressiva e hiperativa são as que mais saem. (Laura)

Pela repetição de um campo de argumentação surge um nome: hiperativo. Depois o sujeito passa a ser apenas a palavra de sua nomeação. Ele passa a ser o diagnóstico, evocando a ideia daquele "duplo" descrito por Foucault (2002).

O diagnóstico, no entanto, pode ter outros efeitos. Podemos ter, como um ganho secundário, o movimento em busca de um entendimento para uma situação geradora de sofrimento. Porque o diagnóstico "chama" as pessoas para a clínica? Por que as pessoas têm o desejo e pedem o diagnóstico? O diagnóstico inventa sentido, oferece uma explicação, uma narrativa, uma história de vida ali onde, em um primeiro momento, havia um "vazio". A medicina, por meio de sua extrema valorização da dimensão biológica, com todos os riscos de simplificação, oferece sentidos de existência e indica alternativas predominantemente químicas. Funcionam como possibilidades assépticas de explicar. A medicina oferece ainda sociabilidade, pertencimento, grupo de ajuda, espaço de convívio, sentido. Como estamos vivendo em uma sociedade amplamente medicalizada, acreditamos nesse modo de fazer sentido.

Outro fator importante, referido por meio dos registros médicos, é o da desculpabilização. Na maior parte das vezes o diagnóstico não culpa, ele (des)culpa. Com o diagnóstico, a pessoa pode deixar de estar implicada no seu sofrimento, assim como a escola e as famílias podem evitar seu compromisso gerador quando têm um "argumento médico". Mas é preciso olhar mais um pouco, há outros efeitos. Esse processo responde a uma desculpabilização construída historicamente, produzida pela pedagogia, pela medicina e pela sociedade. A ideia, ao final, evoca uma culpa que recai sobre o sujeito, a criança passa a ser culpada por não conseguir parar. É culpada porque não presta atenção. Em sintonia com a ausência de responsabilização dos profissionais envolvidos, essa família pode ser culpada porque não deu limite para seu filho. Existe uma produção de uma história moral e educacional de produção de culpados. 
$\mathrm{Na}$ interrupção desse processo surge o alívio a partir de uma resposta medicamentosa. Esse pode ser um dos efeitos do diagnóstico e um dos fatores pelos quais é tão solicitado. Tem um efeito muito potente observado nas falas das pessoas, como uma sensação de alívio.

Quando consideramos o discurso das educadoras sobre a Atenção parece existir uma falta, uma ausência de um saber pedagógico que dê suporte a questões relativas ao campo. Identificamos um vazio do discurso escolar onde deveríamos encontrar argumentos da escola em relação à possibilidade de ensinar a tais crianças. Reconhecemos outros elementos presentes nos discursos das professoras que contam de um desamparo. Desamparo de crianças e de professoras.

Esse desamparo, algumas vezes, ficou traduzido em um corpo em movimento referido pelo diagnóstico de hiperativo. Crianças nomeadas como hiperativas pela escola viviam, em sua maioria, uma forma de cuidado que parecia ser dissociada da capacidade de se interrogar: como posso também eu contribuir para que o outro seja assim? Por meio dos relatos, foi possível perceber nessas crianças diferentes modos de interação e de envolvimento com as tarefas, dependendo do contexto criado na situação escolar. Identificadas como hiperativas, crianças capazes de se organizar e se dedicar demoradamente a brincadeiras complexas reagem de forma negativa quando lhes é proposta a interrupção brusca daquela brincadeira. Estas questões interpelam o campo pedagógico e colocam em discussão o sujeito e as possibilidades de um currículo que o reconheça.

Nos últimos anos está ocorrendo uma rápida mudança quanto à idade em que bebês e crianças pequenas iniciam seu percurso escolar. Esse processo torna-se cada vez mais precoce com a obrigatoriedade da escolarização a partir dos quatro anos de idade, no Brasil, instituída por meio da Lei no ${ }^{\circ}$ 12.796/2013 (BRASIL, 2013). A tendência, portanto, é de intensificação dos fenômenos analisados ao longo do presente texto.

Laura, uma das educadoras entrevistadas, conta sobre sua história acadêmica e o seu distanciamento na relação com os desafios atuais.

Quando eu fiz faculdade eu tinha estágios. Primeiro de zero a três e depois de três a seis no curso de Pedagogia. Mas bebê? [...] Nós pegamos o "modelito" do Ensino Fundamental e colocamos para o jardim B. Do jardim B trouxemos para baixo... E o que se ensina para bebês?

Esta professora destaca a ausência de uma construção curricular que toma seus alunos como parâmetro. As considerações de Laura nos fazem perceber uma falta de reflexão teórica sobre o que é constituir uma infância em tempo de escola infantil. Se é possível identificar 
ausências sobre essa infância na escola, podemos também nos interrogar sobre os processos de valorização da atenção como premissa comportamental típica da história da instituição escolar, como produtora dos fenômenos da suposta desatenção e de seus supostos déficits associados. Laura segue contando sobre as crianças, professoras, escolas deste tempo:

Temos muitas crianças sofrendo. Então a gente tem mesmo muita criança que não está a fim do mundo. Que está na agitação. Que está se agitando ou está desligada.

Professores em movimento de desamparo apresentando dificuldades para saber como organizar a dinâmica escolar, apesar de existirem espaços de diálogo e acompanhamento sistematizado em um serviço de apoio presente há muitos anos na rede de ensino em questão. Há muitas interrogações possíveis a partir das temáticas analisadas. Qual o trabalho pedagógico a ser proposto para esses bebês? O que é currículo para crianças tão pequenas?

Eu vi casos de crianças que num turno ficavam sempre agitadas... O tempo todo buscando essa questão de sair fora da sala e tal... E no outro turno conseguindo parar. E o que eu percebi foi a questão do acolhimento, do colo, do jeito da fala. (Valéria)

O acolhimento dessas questões passa, segundo acreditamos, pela retomada de premissas pedagógicas no sentido de que aprender e ensinar são fenômenos indissociáveis que resultam de investimento no ato de conhecer o outro, oferecer-lhe suporte para que avance em suas estratégias de apropriar-se do mundo e de afirmar-se em sua condição de sujeito.

\section{Considerações finais}

Encontramos indícios do discurso médico presente nas escolas, agindo para dar forma ao olhar dirigido aos sujeitos, além de uma proposição de intervenção que não valoriza as relações, mas um corpo a ser 'tratado'. A interlocução entre escola e saber médico resulta em uma negociação e uma confluência: o diagnóstico de hiperatividade e desatenção centrado em suas manifestações e suas condutas.

O olhar valorizador do fenômeno hiperatividade, segundo nosso entendimento e considerando os autores que nos dão sustentação, reafirma uma direção simplificadora: centrar no aspecto biológico e cerebral a constituição de um sujeito em detrimento do entendimento de que se trata de um fenômeno produzido na relação entre as pessoas. Em função das premissas apresentadas, das bases teóricas que contribuem com nossas reflexões e 
dos indícios do trabalho de escuta de nossas interlocutoras, consideramos que, apesar da tendência à valorização da dimensão biológica, constitutiva no entendimento e na atenção às manifestações da hiperatividade, é possível identificar uma pluralidade de fatores intervenientes na constituição dos sujeitos identificados como hiperativos. Esse processo exige de nós uma disposição para considerar o sujeito em sua complexidade e sua necessária singularidade, além de nos mostrar a potência do trabalho contextual e educativo.

Poderíamos, valorizando nosso movimento de "atenção flutuante", conseguir um deslocamento de olhar daquilo frequentemente identificado com 'desatenção na aprendizagem' para uma perspectiva que nos propusesse a aprendizagem da Atenção. Essa é uma perspectiva potente para se refletir sobre o trabalho educativo, pois indica possíveis frutos desse investimento, além de ser um desdobramento de uma evidência empírica que se mostra a todos os educadores: os sujeitos considerados hiperativos não são os mesmos em qualquer contexto. Diante de diferentes interlocutores, temos diferentes respostas, e muitas destas surpreendem pela emergência de dedicação e envolvimento.

A partir desse ponto de vista, podemos reconhecer de um lado a potência da intervenção educativa e, de outro, a necessidade de apoio que se constitua como múltiplos pontos de sustentação para os diferentes sujeitos implicados, pois os sinais de desamparo são difusos. O não acolhimento desses sinais tende a perpetuar as dinâmicas que se mostram como sintomáticas e aprisionam cada sujeito ao seu 'personagem'.

Partindo da premissa da Atenção como uma função construída, o que ganha visibilidade é um leque de possibilidades associadas à intervenção pedagógica. Fazemos esse destaque entendendo que a escola poderia, caso reconhecesse esse processo produtor de Atenção, intensificar movimentos no sentido de promover o cuidar/atender a seus alunos.

\section{REFERÊNCIAS}

AMADOR, F.; FONSECA, T. M. G. Da intuição como método filosófico à cartografia como método de pesquisa: considerações sobre o exercício cognitivo do cartógrafo. Arquivos Brasileiros de Psicologia, Rio de Janeiro, v. 61, n. 1, p. 30-37, abr., 2009.

ANGELUCCI, C. B; SOUZA, B. P. Apresentação. In: Conselho Regional de Psicologia, Grupo Interinstitucional Queixa Escolar (Orgs.). Medicalização de Crianças e

5 Tomamos a ideia de "Atenção Flutuante" de Freud, aqui redesenhada a partir de nossas próprias inferências e de autores, como Michel Foucault, que discutem uma dinâmica contextual que mostra e oculta fragmentos a partir do olhar do sujeito. 
Adolescentes: Conflitos silenciados pela redução de questões sociais a doenças de indivíduos. Ed. Casa do psicólogo, São Paulo, 2010.

BRASIL. Ministério da Educação. Lei no 12.796, de 04 de abril de 2013. Altera a Lei no 9.394, de 20 de dezembro de 1996. Brasília, 2013. [online]. Disponível em:

http://www.planalto.gov.br/ccivil_03/_ato2011-2014/2013/lei/l12796.htm. Acesso em: 5 jul. 2018.

BATESON, G. Mente e natureza. Rio de Janeiro: Francisco Alves, 1993.

BENINCASA, M. C. Educação especial e educação infantil: uma análise de serviços de apoio no município de Porto Alegre. 2011. 126 f. Dissertação (Mestrado em Educação) - Programa de Pós-Graduação em Educação, Universidade Federal do Rio Grande do Sul, Porto Alegre, 2011.

CALIMAN, L. V. A biologia moral da atenção: a constituição do sujeito (des)atento. 2006. 176 f. Tese (Doutorado em Saúde Coletiva) - Programa de Pós-Graduação em Saúde Coletiva, Instituto de Medicina Social Universidade do Estado do Rio de Janeiro, Rio de Janeiro, 2006.

CALIMAN, L. V. Notas sobre a história oficial do Transtorno do Déficit de Atenção/hiperatividade TDAH. Psicologia, Ciência e Profissão, v. 30, n. 1, p. 45-61, 2010.

CANGUILHEM, G. O Normal e o patológico. Rio de Janeiro: Forense Universitária, 2000. FERNÁNDEZ, Alicia. Os Idiomas do aprender. Porto Alegre: Artes Médicas, 2001. FRANCES, A. Primo, non curare chi è normale. Millano: Bollati Boringhieri, 2013. FOUCAULT, M. Microfísica do poder. Rio de Janeiro: Graal, 1992.

FOUCAULT, M. Os Anormais. Curso no Collège de France (1974-1975). São Paulo: Martins Fontes, 2002.

FREITAS, C. R.; BAPTISTA, C. R. A atenção, a infância e os contextos educacionais. Psicologia \& Sociedade. Belo Horizonte, v. 29, n. e140387, p. 1-9, jul., 2017.

ITABORAHY, C. A Ritalina no Brasil: uma década de produção, divulgação e consumo. 2009. 126 f. Dissertação (Mestrado em Saúde Coletiva) - Programa de Pós-Graduação em Saúde Coletiva, Universidade Estadual do Rio de Janeiro, Rio de Janeiro, 2009.

KASTRUP, V. O funcionamento da atenção no trabalho do cartógrafo. In: PASSOS, E.; KASTRUP, V.; ESCÓSSIA, L. (Orgs.) Pistas do método da cartografia: pesquisaintervenção e produção de subjetividade. Porto Alegre: Sulina, 2009.

ROSE, N. La politica della vita. Torino: Giulio Enaudi, 2008. 
UNTOIGLICH, G. Consenso de especialistas da área de saúde sobre o chamado "Transtorno por déficit de atenção com ou sem hiperatividade". Diagnóstico na Infância hoje. APPOA Associação Psicanalítica de Porto Alegre. POA. Correio APPOA, nº144, 2006.

\section{Como referenciar este artigo}

FREITAS, Cláudia Rodrigues de.; BAPTISTA, Claudio Roberto. Mais rápidas que a escola: crianças referidas como hiperativas no contexto escolar. Revista Ibero-Americana de Estudos em Educação, Araraquara, v. 14, n. esp. 1, p. 791-806, abr., 2019. E-ISSN: 19825587. DOI: 10.21723/riaee.v14iesp.1.12207

Submetido em: 06/08/2018

Aprovado em: 21/09/2018 